\title{
MGBG in Combined Anticancer Chemotherapy
}

\author{
R.F. Gonçalves ${ }^{1}$, G. Kriechammer ${ }^{1}$ and M.P.M. Marques*,1,2 \\ ${ }^{1}$ Research Unit “Molecular Physical Chemistry”, University of Coimbra - Portugal \\ ${ }^{2}$ Departament of Life Sciences, Faculty of Science and Technology, University of Coimbra - Portugal \\ Received June 06, 2011: Revised August 24, 2011: Accepted August 24, 2011
}

\begin{abstract}
The combined activity of MGBG (metylglyoxal-bis(guanylhydrazone)) with either cisplatin or carboplatin was investigated, towards the human breast cancer cell line MCF-7. While a dose- and time-dependent cytotoxic activity was already observed for MGBG alone, a synergistic and non-reversible effect was verified upon co-administration with these Pt-based drugs. Furthermore, toxicity against non-neoplastic cells was shown to be quite low for these drug cocktails, as opposed to either Pt-agents alone. These results may hopefully allow to use lower dosages of both MGBG and the Ptdrugs, minimising the drug's deleterious side effects while keeping antitumour efficacy, in an anticancer strategy that couples interference with polyamine homeostasis with DNA damage.
\end{abstract}

Keywords: Anticancer, Breast cancer, Carboplatin, Cisplatin, MGBG.

\section{INTRODUCTION}

Methylglyoxal-bis(guanylhydrazone) (mitoguazone or MGBG, Fig. 1) structurally related to the biogenic polyamine spermidine, has been widely studied since the discovery (in 1972) of its selective inhibitory action against S-adenosylmethionine decarboxylase $(\mathrm{SAM} d c)[1,2]$. This direct involvement in biogenic polyamine biosynthesis (spermidine and spermine) [3-6], known to be significantly deregulated in pre-carcinogenic and carcinogenic states [7], prompted the study of this compound as a potential antineoplastic agent, either alone or in combination with conventional drugs.

MGBG's cytotoxicity was first demonstrated in the 1960 's, towards acute myelogenous leukaemia $[8,9]$ but it was quickly abandoned as an anticancer agent due to its severe side-effects (e.g. mucositis and myelosuppression [10]). Nevertheless, it was later rediscovered, when new clinical trials demonstrated that its scheduled (weekly) administration strongly decreases MGBG's toxicity while preserving its antitumour properties, particularly in Hodgkin's and non-Hodgkin's lymphoma [4]. Moreover, its use in combined therapy has shown to yield promising results in several types of cancer, namely myeloid leukemia (with difluormethylornithine ( $\alpha$-DFMO) [9], refractory lymphoma (with cisplatin [11]) or breast cancer (with 2'2'difluorodeoxycytidine (Gemcitabine) [5]).

Breast cancer represents $14 \%$ of female cancer deaths worldwide [12], more than one million cases being detected each year. Although extensive preclinical and clinical studies have resulted in modest success in decreasing the morbidity of this type of neoplasia, no successful chemotherapeutic drug is yet available to control the disease. In estrogendependent breast cancers such as MCF-7 cell growth is controlled by regulating hormonal factors, namely estrogens.

*Address correspondence to this author at the Departamento de Ciências da Vida, Faculdade de Ciências e Tecnologia, Universidade de Coimbra, Apartado 3046, 3001-401 Coimbra, Portugal; Tel: +351 239826541; Fax: +351 239854448; E-mail: pmc@ci.uc.pt
Therefore, one of the most common chemotherapeutic practices against this kind of neoplasias is administration of antiestrogens, either targeting estrogen synthesis (e.g. aromatase inhibitors) or estrogen receptors (selective estrogen receptor modulators, SERM's). However, most tumours eventually develop resistance to this type of therapy. Additionally, MCF-7 human breast cancer cells are relatively resistant to cisplatin treatment compared to other breast cancer cell lines, and this is further limited by the drug-related adverse effects $[13,14]$. Therefore, the development of alternative therapeutic strategies against this type of breast cancer is of paramount importance, namely by enhancing the cells' sensitivity to cisplatin (or other Pt-based conventional drugs) [15], or through combination of antitumour agents with distinct mechanisms of action.

In the present study, the effect of co-administration of MGBG with either cisplatin (cis- $\left.\left(\mathrm{NH}_{3}\right)_{2} \mathrm{PtCl}_{2}, \mathrm{cDDP}\right)$ or carboplatin $\left(\mathrm{Pt}\left(\mathrm{NH}_{3}\right)_{2} \mathrm{C}_{6} \mathrm{O}_{4} \mathrm{H}_{6}\right)$ (Fig. 1) was investigated, towards the estrogen-dependent human cancer cell line MCF-7. A sinergistic effect between these two agents is sought, by targetting two distinct mechanisms of action: interference with the polyamine homeostasis (MGBG) and with DNA replication and transcription (Pt-based compounds). Both cell-growth and cell viability were evaluated, as well as the reversibility of the cytotoxic effect and the toxicity towards non-carcinogenic cells (nonimmortalised, BJ human foreskin fibroblasts).

\section{MATERIALS AND METHODS:}

\section{Chemicals}

Cisplatin, carboplatin, dimethylsulfoxide (DMSO), 3(4,5-dimethylthiazol-2-yl)-2,5-diphenyl-tetrazolium bromide (MTT), Dulbecco's modified Eagle's high glucose medium (DMEM-HG), phosphate-buffered saline (PBS) solution, sulforhodamine B (SRB) and Trypan blue (0.4\% solution) were purchased from Sigma-Aldrich Chemical Co. (Sintra, Portugal). Antibiotics (penicillin-streptomycin 100x solution) and methylglyoxal-bis(guanylhydrazone) (MGBG) were obtained from Janssen (Belgium). Fetal calf serum 

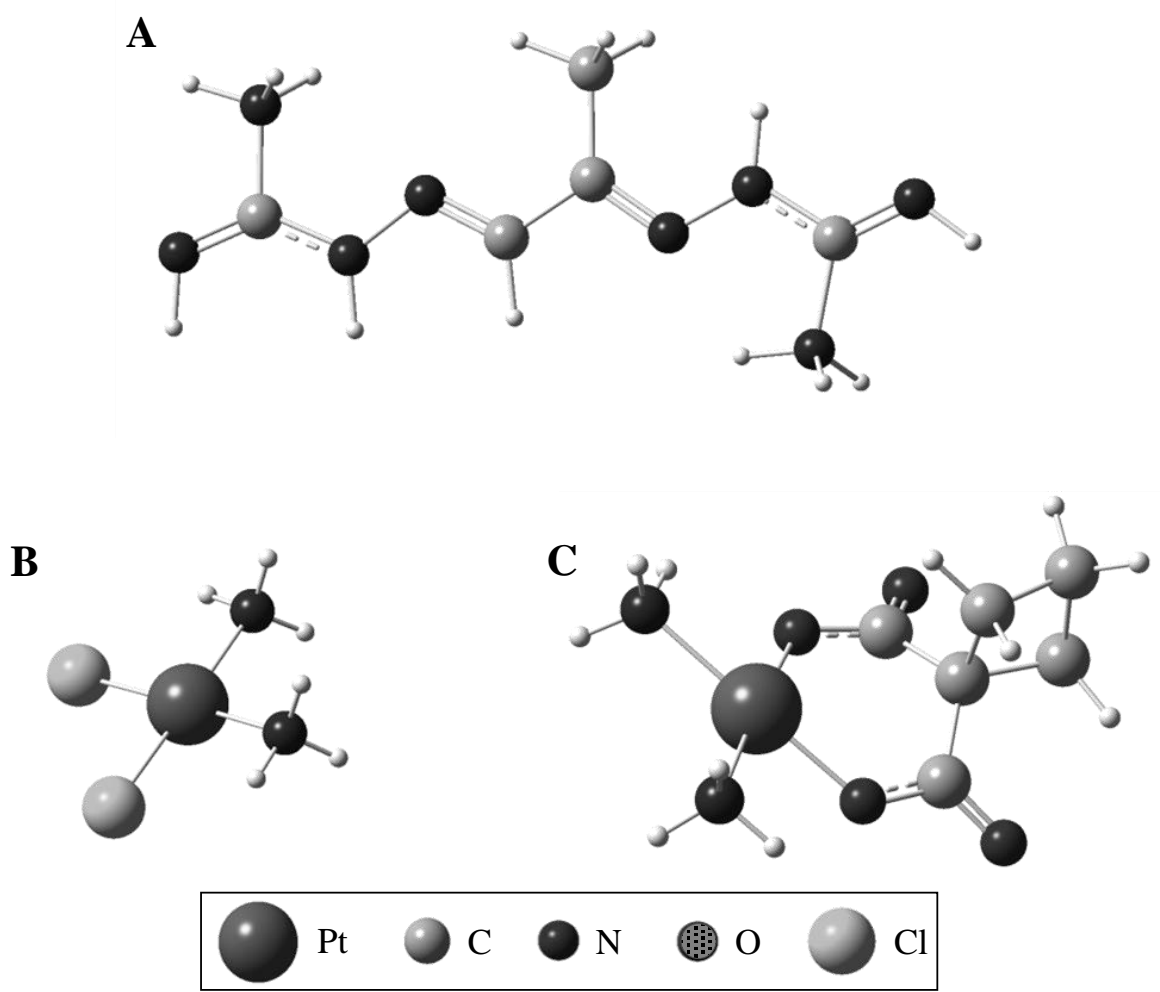

Fig. (1). Structural representation of the compounds under study: (A) - MGBG; (B) - cisplatin; (C) - carboplatin.

(FCS), trypsin-EDTA $(0,05 \%)$. All the other reagents (pro analysis grade) were obtained from Sigma-Aldrich Chemical Co. (Sintra, Portugal).

\section{Cell Lines}

The human breast estrogen-receptor positive (ER+) adenocarcinoma cell line MCF-7 was kindly made available by the Centre for Neuroscience and Cell Biology (CNC) of the University of Coimbra, while the non-carcinogenic, nonimmortalised, human foreskin fibroblast cells (BJ) were purchased from the American Type Culture Collection (CRL-2522 ${ }^{\mathrm{TM}}$, ATCC, USA).

\section{Preparation of Solutions}

MGBG, cDDP and carboplatin stock solutions were prepared in phosphate-buffered saline (PBS) solution to the desired concentrations (Table 1) and sterilised by filtration.
MTT was prepared, in a concentration of $0.5 \mathrm{mg} / \mathrm{mL}$, in PBS solution. SRB was used as a $0,5 \%(w / v)$ solution, in $1 \%(v / v)$ acetic acid.

\section{Cell Culture}

The cells were grown as monolayers, at $37^{\circ} \mathrm{C}$, in a humidified atmosphere of $5 \% \mathrm{CO}_{2}$, in DMEM-HG (4500 $\mathrm{mg} / \mathrm{mL}$ ) medium, supplemented with $10 \%$ heat inactivated fetal calf serum, glutamine $(13,4 \mathrm{~g} / \mathrm{L})$, antibiotics (100 units of penicillin and $100 \mathrm{mg}$ streptomycin) and 1,5 g sodium bicarbonate $(\mathrm{pH} \mathrm{7,4)}$. The cell lines were subcultured when $85 \%$ confluence was attained, by washing with PBS and trypsinising with $0,05 \%$ trypsin-EDTA solution.

\section{Antiproliferative Activity}

The antiproliferative activity of MGBG was evaluated towards the MCF-7 cell line, using the SRB method [16, 17].

Table 1 Systems Under Study and Concentration Range Used in the Biological Assays

\begin{tabular}{|c|c|c|}
\hline & \multicolumn{2}{|c|}{$\begin{array}{c}\text { Concentrations }(\boldsymbol{\mu M}) \\
\text { Cell line }\end{array}$} \\
\hline Drugs & MCF-7 & BJ \\
\hline \hline MGBG & $10,25,50,75,100$ & $5,10,50$ \\
\hline cDDP10/MGBG cocktail & $5,10,20,50,100$ & $5,10,50$ \\
\hline cDDP25/MGBG cocktail & $5,10,20,50,100$ & - \\
\hline Carboplatin25/MGBG cocktail & $5,20,100$ & - \\
\hline
\end{tabular}




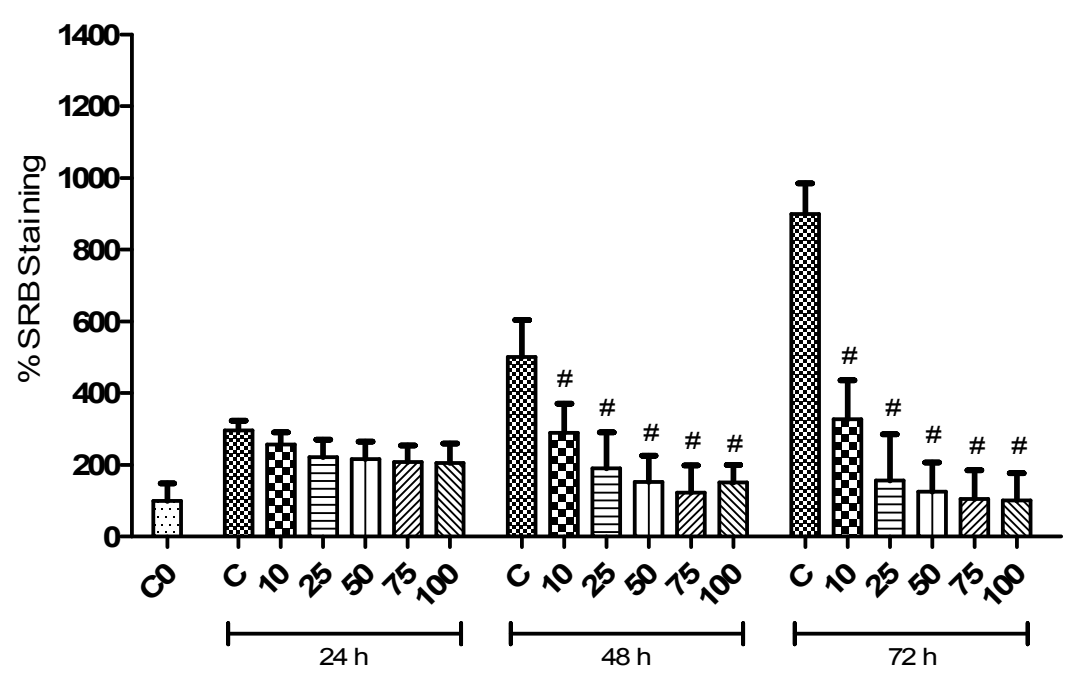

Concentration $(\mu \mathrm{M})$

Fig. (2). Time dependence of the antiproliferative activity of MGBG against the MCF-7 cell line. Cells $\left(3 \times 10^{4}\right.$ cells/ $\left.\mathrm{cm}^{2}\right)$ were incubated with the compounds for periods of 24 to $72 \mathrm{~h}$. Every $24 \mathrm{~h}$ the cell density was measured by the SRB colorimetric assay. The drug was removed $72 \mathrm{~h}$ after seeding, and the cell growth was assessed following a further $72 \mathrm{~h}$ incubation. The data are expressed as a percentage of the control SRB staining, and represents the average \pm SD from three independent experiments carried out in triplicate $\left({ }^{\#} p<0.0001\right)$.

The cells were seeded for $24 \mathrm{~h}$, at a density of $3.0 \times 10^{4}$ cells per well (in 24-wells plates), prior to adding the compounds. The cells were counted every $24 \mathrm{~h}$, for a total exposure period of $72 \mathrm{~h}$. The compound-containing medium was removed, the cells were fixed (in cold $1 \%$ acetic acid:methanol $(v: v))$ and incubated for $2 \mathrm{~h}$ at $4^{\circ} \mathrm{C}$. Upon air drying, $0.5 \%(w / v)$ SRB in $1 \%$ acetic acid was added. At the end of the staining period $\left(1 \mathrm{~h}\right.$ at $\left.37^{\circ} \mathrm{C}\right)$, the unbound SRB was washed with $1 \%$ acetic acid. The plates were air-dried again and the cell-bound dye was solubilized in $10 \mathrm{mM}$ aqueous Tris base. The plates were shaken, and the absorbance mesured at $540 \mathrm{~nm}$, yielding the cell density values.

\section{Cytotoxic Activity and Reversibility of the Compounds' Effect}

Cell viability as a function of the compounds' concentration - MGBG and cDDP:MGBG - was determined for both cell lines studied, at a density of $3.0 \times 10^{4}$ cells per well (24-wells plates for MCF-7 and 48-wells plates for BJ). The carboplatin:MGBG cocktails were screened only towards the MCF-7 cell line. The cells were seeded for $24 \mathrm{~h}$ prior to adding the tested agents. Culture analysis was performed every $24 \mathrm{~h}$, for a total period of 48 and $72 \mathrm{~h}$ for the BJ and MCF-7 lines, respectively. A MTT solution (0.5 $\mathrm{mg} / \mathrm{mL})[18,19]$ was then added to each well. After $3 \mathrm{~h}$ incubation at $37{ }^{\circ} \mathrm{C}$, the formed formazan crystals were
(A)

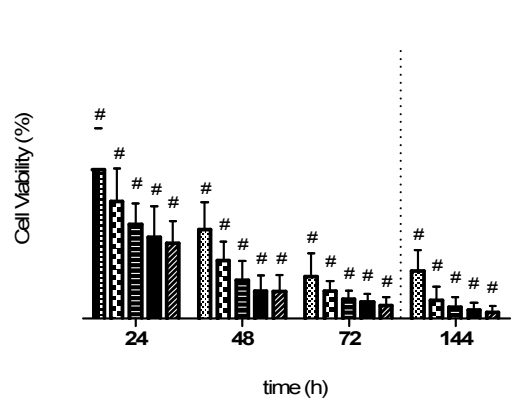

(B)

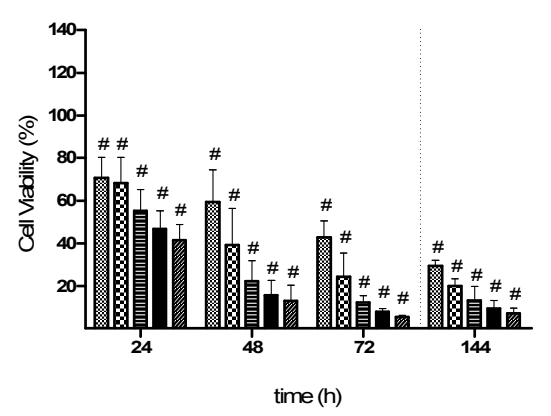

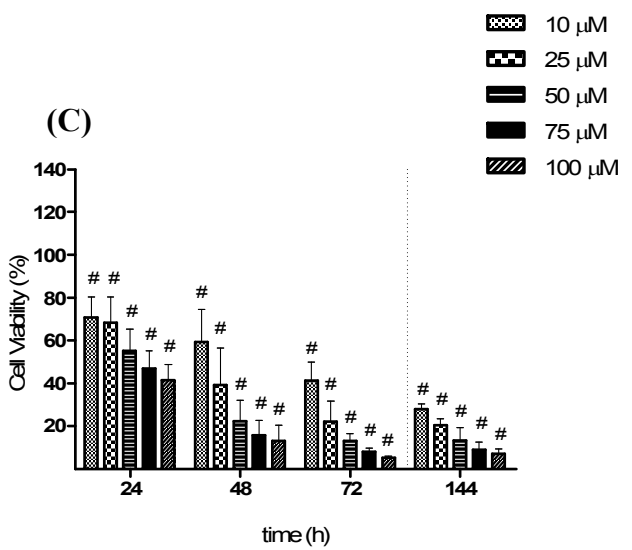

Fig. (3). Time dependence of the cytotoxic effect of the compounds studied against the MCF-7 cell line: (A) MGBG, (B) cDDP10/MGBG and (C) cDDP25/MGBG. Cells $\left(3 \times 10^{4}\right.$ cells/ $\left./ \mathrm{cm}^{2}\right)$ were incubated with the compounds for periods of 24-72 $\mathrm{h}$. Cells $\left(3 \times 10^{4}\right.$ cells $\left./ \mathrm{cm}^{2}\right)$ were incubated with the compounds for periods of 24 to $72 \mathrm{~h}$. Every $24 \mathrm{~h}$ the cell viability was evaluated by the MTT colorimetric assay. The drug was removed $72 \mathrm{~h}$ after seeding, and the viability was assessed following a further $72 \mathrm{~h}$ incubation. The data are expressed as a percentage of the control MTT reduction $(100 \%)$, and represent the average \pm SD from three independent experiments carried out in triplicate $(\# p<0.0001)$. 
(A)

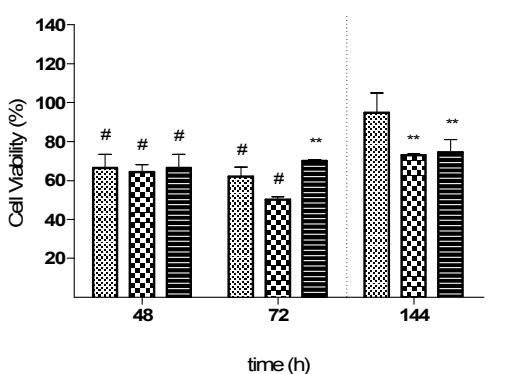

(B)

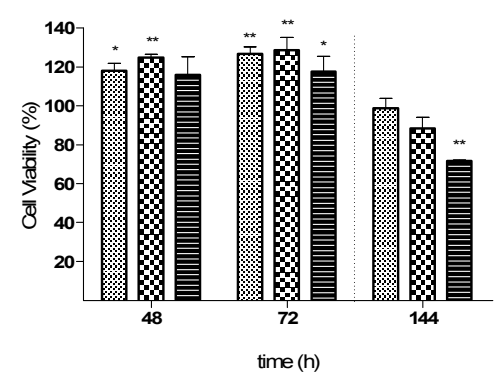

(C)

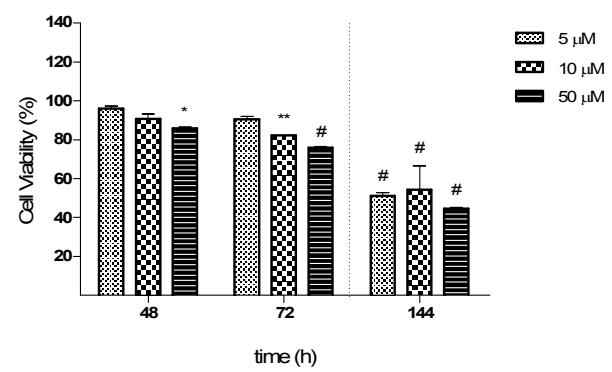

Fig. (4). Time dependence of the cytotoxic effect of the compounds studied against the BJ cell line: (A) MGBG, (B) cDDP10/MGBG and (C) cDDP25/MGBG. Cells $\left(3 \times 10^{4}\right.$ cells $\left./ \mathrm{cm}^{2}\right)$ were incubated with the compounds for periods of $24-72 \mathrm{~h}$. Cells $\left(3 \times 10^{4} \mathrm{cells} / \mathrm{cm}^{2}\right)$ were incubated with the compounds for periods of 24 to $72 \mathrm{~h}$. Every $24 \mathrm{~h}$ the cell viability was evaluated by the MTT colorimetric assay. The drug was removed $72 \mathrm{~h}$ after seeding, and the viability was assessed following a further $72 \mathrm{~h}$ incubation. The data are expressed as a percentage of the control MTT reduction (100\%), and represent the average \pm SD from one independent experiments carried out in duplicate $(* p<0.05$; $* * p$ $<0.001$ and $\left.{ }^{\#} p<0.0001\right)$.

solubilized in dimethylsulfoxide. Finally, the absorbance was measured at $570 \mathrm{~nm}$, and cell viability was determined.

In order to assess the reversibility of this cytotoxic activity, the drug-containing culture medium was removed and fresh medium was added in the last day of incubation, and the cell viability was obtained after $72 \mathrm{~h}$ through the MTT test (Figs. 2 to 5).

\section{Statistical Analysis}

The experiments with the MCF-7 cells were performed in triplicate, in three independent assays. Preliminary studies with the BJ cell line were performed in duplicate, in one experiment. The results are expressed as means \pm SD and compared with the non-treated controls. Statistical analysis were carried out using One-Way ANOVA, followed by Turkey's post-test for the SRB assays, and by Dunnett's post-test for the MTT tests. Statistical comparison between the data was based on the Pearson correlation coefficient, values with $\mathrm{p}<0.05$ being considered as significant.

\section{RESULTS AND DISCUSSION}

The polyamine antimetabolite MGBG was evaluated as to its antiproliferative and cytotoxic properties towards the estrogen-receptor positive $(\mathrm{ER}+)$ human breast cancer cell line MCF-7, both alone and co-administered with the conventional Pt-based drugs cisplatin or carboplatin (Table 1).

The results obtained by the sulforhodamine B method [17] evidence that MGBG exhibits a dose and timedependent antiproliferative effect towards this cell line, for the concentration range between 10 and $100 \mu \mathrm{M}$, after $48 \mathrm{~h}$ of incubation (Fig. 2). This is in agreement with the conclusions attained in a previous study performed in
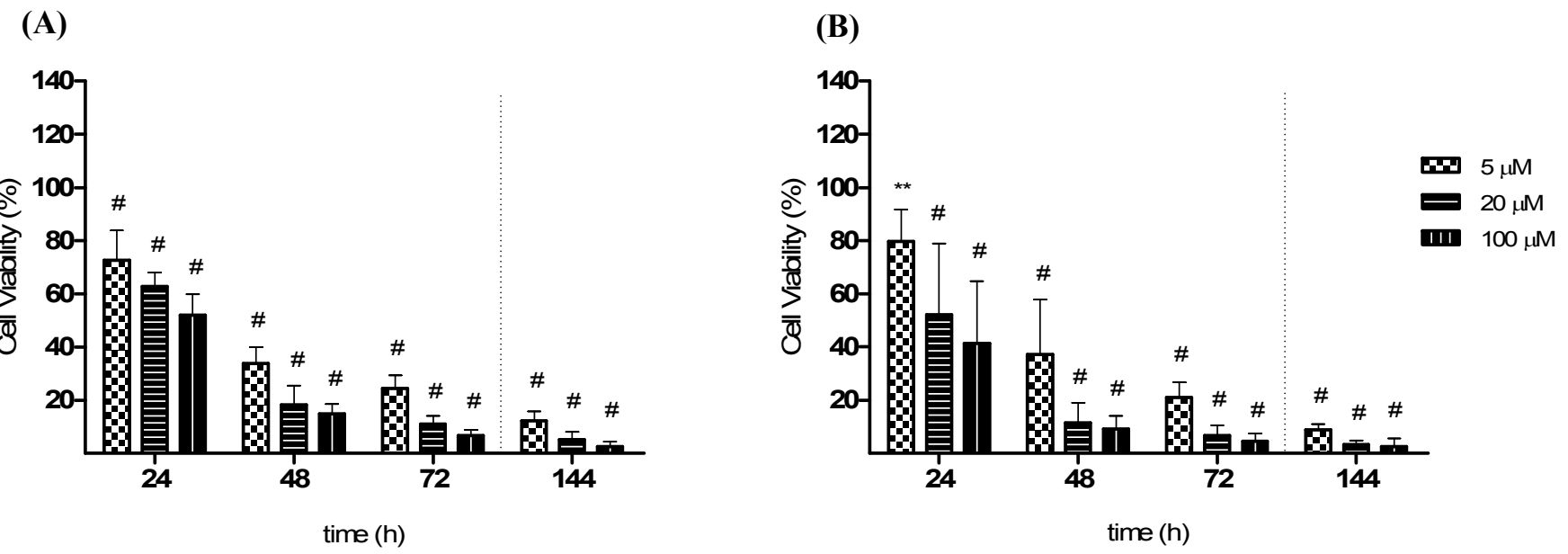

Fig. (5). Time dependence of the cytotoxic effect of the compounds studied against the MCF-7 cell line: (A) carboplatin25/MGBG and (B) carboplatin50/MGBG. Cells $\left(3 \times 10^{4}\right.$ cells $\left./ \mathrm{cm}^{2}\right)$ were incubated with the compounds for periods of $24-72 \mathrm{~h}$. Cells $\left(3 \times 10^{4}\right.$ cells $\left./ \mathrm{cm}^{2}\right)$ were incubated with the compounds for periods of 24 to $72 \mathrm{~h}$. Every $24 \mathrm{~h}$ the cell viability was evaluated by the MTT colorimetric assay. The drug was removed $72 \mathrm{~h}$ after seeding, and the viability was assessed following a further $72 \mathrm{~h}$ incubation. The data are expressed as a percentage of the control MTT reduction $(100 \%)$, and represent the average \pm SD from three independent experiments carried out in triplicate $(* * p<0.001$ and $\left.{ }^{\#} p<0.0001\right)$. 
cultures of rat hepatocytes [20] as well as on a reported study on human histiocytic lymphoma that evidenced a decrease in protein synthesis after 20 to $25 \mathrm{~h}$ of exposure to the compound [21]. MGBG's antiproliferative activity is suggested to be delayed due to conformational rearrangements undergone by the molecule at physiological conditions (since several species, with distinct activities, may coexist in the plasma).

MGBG's cytotoxic effect was also evaluated (Fig. 3), through the MTT assay for mitochondrial dehydrogenase activity [16, 18, 19]. Exposure to MGBG led to a cell viability decrease that progresses over incubation time (from 24 to 72 hours). This may be related to changes in mitochondrial permeability due to reduction of the intracellular concentration of spermidine and spermine, since these are known to play a key role in the inhibition of mitochondrial permeability transition [22, 23]. This cytotoxic effect was found to be irreversible, as the cells could not recover and viability was kept at low values upon MGBG removal from the cell culture medium (after $72 \mathrm{~h}$ of exposure). Also, this compound provided a larger cytotoxicity than cisplatin, for the same cancer line and concentration range [personal data, unpublished].

MGBG's cellular uptake is proposed to occur through the transport system of biogenic polyamines [20]. By inhibiting S-adenosylmethionine decarboxylase, it leads to a decrease of the spermidine and spermine intracellular concentration, consequently reducing in vitro cell growth and viability. This diminished polyamine pool affects DNA synthesis [1] by destabilization of the DNA molecule, as previously demonstrated in human leukemia cells (HL-60) [24].

Knowing that MGBG displays significant antiproliferative and cytotoxic activities against the breast cancer line MCF-7 (Figs. 2 and 3), its effect when combined with the chemotherapeutic drugs cisplatin (cDDP) or carboplatin was assessed. These experiments were performed by using a mixture of the two compounds, with varying concentrations of MGBG and a constant cDDP or carboplatin dosage. The results for cDDP:MGBG, comprised in Figs. (3B and $\mathbf{3 C}$ ) for a cisplatin concentration of 10 and $25 \mu \mathrm{M}$, respectively, evidence a clear cytotoxicity towards the MCF-7 cells, already for $25 \mu \mathrm{M}$ MGBG after 48 hours of incubation, attaining a maximum ( $\mathrm{ca}$. 7\% cell viability) at 72 hours of drug exposure, for MGBG's highest concentration $(100 \mu \mathrm{M})$. Irreversibility of the drug effect was also observed for these cocktails, probably as a result of a twofold mechanism: formation of cDDP-DNA adducts responsible for an irreversible damage (e.g. through inefficiency of the cell repair mechanisms $[25,26]$, coupled to the MGBG inhibitory action at the polyamine level (interference with polyamine biosynthesis). These results reflect a significant sinergistic effect between MGBG and cisplatin: viability decrease of $c a$. $17 \%$ upon a $72 \mathrm{~h}$ incubation with cDDP-10 $\mu \mathrm{M}$ :MGBG-50 $\mu \mathrm{M}$, as compared to a viability loss of $40 \%$ for the same cDDP dosage and identical experimental conditions [27, 28].

Similarly, co-administration of MGBG and carboplatin caused a more pronounced cytotoxicity relative to each of the two isolated compounds (Fig. 5, Table 2). Also, this synergistic effect was more pronounced than for the cDDP:MGBG cocktails: the same drug dosage $(25 \mu \mathrm{M})$ led to a much lower $\mathrm{LD}_{50}$ in the case of carboplatin $-1.268 \mathrm{vs}$ 7.825 (Table 2). Nevertheless, maximum cytotoxicity was verified for longer incubation times than for the cDDP cocktails, as a consequence of the slower hydrolysis kinetics of carboplatin [29], which leads to a longer time for drug activation within the cell. Actually, cisplatin's chloride atoms are expected to undergo an easier substitution than carboplatin's leaving groups [30].

The $\mathrm{LD}_{50}$ values (lethal dosis of drug yielding a $50 \%$ of cell viability decrease) were determined for all the compounds tested (Table 2). Both cDDP:MGBG and carboplatin:MGBG cocktails were responsible for lower $\mathrm{LD}_{50}$ dosages as compared to cDDP alone, for 48 and $72 \mathrm{~h}$ incubation times. Relative to MGBG, however, a sinergism was only verified for $48 \mathrm{~h}$ of drug exposure.

In order to assess the degree of toxicity of the agents under study towards non-neoplastic cells, experiments were carried out against non-immortalised human foreskin fibroblasts (BJ cell line), through the MTT colorimetric assay. Both MGBG and the cDDP:MGBG cocktails were found to induce a relatively low toxicity towards the BJ line - no more than 60-65\% viability loss, even for a $72 \mathrm{~h}$ exposure and a cDDP-25 mM:MGBG-50 $\mu \mathrm{M}$ dosage (Fig. (4C). These observations can be interpreted in the light of physiological differences between neoplastic and nonneoplastic cells, which respond differently to the drug action. In the case of the MCF-7 cell line, the tested agents probably undergo a quick and extensive internalisation as a consequence of the rapid cancer cell growth thus causing a severe and irreversible effect. In turn, human foreskin

Table 2. $\quad \mathrm{LD}_{50}$ Values $(\mu \mathrm{M})$ Towards the MCF-7 Cell Line, for the Compounds

\begin{tabular}{|c|c|c|c|}
\hline & \multicolumn{2}{|c|}{ LD50 $(\boldsymbol{\mu M})$} \\
\hline Drugs & $\mathbf{2 4} \mathbf{~ h}$ & $\mathbf{4 8 ~ h}$ & $\mathbf{7 2 ~ h}$ \\
\hline \hline MGBG & 44.640 & 8.284 & 1.737 \\
\hline cDDP & 56.090 & 30.550 & 3.010 \\
\hline cDDP10/MGBG cocktail & 49.450 & 6.285 & 3.793 \\
\hline cDDP25/MGBG cocktail & 49.450 & 7.825 & 3.429 \\
\hline Carboplatin25/MGBG cocktail & N.A. & 1.268 & 0.845 \\
\hline
\end{tabular}

N.A. - experimental data did not yield convergent results ${ }^{\mathrm{a}}[28]$ 
fibroblasts appear to recover from the MBGB's cytotoxic effect, as the slower dividing cells internalise smaller amounts of compound [2, 31]. This, however, does not discard contribution from other mechanisms, that may differ between cancer and healthy cells.

Co-administration of MGBG and the conventional drugs cisplatin or carboplatin towards the MCF-7 cell line clearly led to a significant synergistic effect relative to the Pt-agent when given separately. This constitutes a promising result regarding the use of $\mathrm{MGBG}$ in newer chemotherapeutic anticancer regimes, since it allows to use lower dosages of both this compound and the Pt-based agents, thus minimising drug's deleterious side effects and acquired resistance.

Furthermore, evaluation of the drug's reversibililty and of its effect on non-neoplastic cell lines (for both MGBG alone and the cocktails) are of paramount importance for assessing effectiveness, administration conditions/patient compliance and toxicity. These are essential parameters to measure and interpret, in view of developing efficient anticancer strategies that couple interference with polyamine homeostasis with DNA damage.

\section{CONCLUSIONS}

MGBG has been shown to affect cell growth and viability through modulation of polyamine intracellular pool, for an estrogen-dependent human breast cancer cell line. Coadministration of this SAMDC inhibitor and the convencional Pt-based drugs cisplatin or carboplatin, in turn, led to a synergetic effect.

This constitutes a promising result regarding the use of MGBG as a part of an anticancer strategy, since allows to use lower dosages, when combined to either cisplatin or carboplatin, thus minimising or even avoiding MGBG's deleterious side effects.

Furthermore, evaluation of the drug's reversibililty (both for MGBG alone and the cocktails) and of its effect on nonneoplastic cell lines are of paramount importance for assessing effectiveness, administration conditions and toxicity. These are essential parameters to measure and interpret, in view of developing efficient anticancer strategies that couple with polyamine homeostasis (via the polyamine biosynthetic pathway).

\section{ACKNOWLEDGEMENTS}

The authors acknowledge financial support from the Portuguese Foundation for Science and Technology - PEstOE/QUI/UI0070/2011 and PhD fellowship SFRH/BD/ 40235/2007 (NFLM).

\section{REFERENCES}

[1] Williams-Ashman, H. G.; Schenone, A., Methyl glyoxal bis(guanylhydrazone) as a potent inhibitor of mammalian and yeast S-adenosylmethionine decarboxylases. Biochem Biophys Res Commun 1972, 46(1), 288-95.

[2] Ferioli, M. E.; Berselli, D.; Caimi, S., Effect of mitoguazone on polyamine oxidase activity in rat liver. Toxicol Appl Pharmacol 2004, 201(2), 105-11.
[3] Seppanen, P.; Fagerstrom, R.; Alhonen-Hongisto, L.; Elo, H.; Lumme, P.; Janne, J., Glyoxal bis(guanylhydrazone) as an inhibitor of polyamine biosynthesis in tumour cells. Biochem J 1984, 221(2), 483-8.

[4] Von Hoff, D. D., MGBG: teaching an old drug new tricks. Ann Oncol 1994, 5(6), 487-93.

[5] Ishmael, D. R.; Chen, W. R.; Nordquist, J. A.; Liu, H.; Nordquist, R. E., Synergistic effect of sequential administration of mitoguazone (MGBG) and gemcitabine in treating tissue cultured human breast cancer cells and mammary rat tumors. Cancer Invest 2003, 21(2), 217-26.

[6] Wallace, H. M.; Fraser, A. V., Inhibitors of polyamine metabolism: review article. Amino Acids 2004, 26(4), 353-65.

[7] Nishioka, K., International Symposium on Polyamines in Cancer. Critical role of polyamines in cancer: basic mechanisms and clinical approaches. Cancer Res 1993, 53(11), 2689-92.

[8] Freireich, E. J.; Frei, E., 3rd; Karon, M., Methylglyoxal bis (guanylhydrazone): a new agent active against acute myelocytic leukemia. Cancer Chemother Rep 1962, 16, 183-6.

[9] Gastaut, J. A.; Tell, G.; Schechter, P. J.; Maraninchi, D.; Mascret, B.; Carcassonne, Y., Treatment of acute myeloid leukemia and blastic phase of chronic myeloid leukemia with combined eflornithine (alpha difluoromethylornithine) and methylglyoxal-bisguanyl hydrazone (methyl-GAG). Cancer Chemother Pharmacol 1987, 20(4), 344-8.

[10] Regelson, W.; Holland, J. F., Initial clinical study of parenteral methylglyoxal bis(guanylhydrazone) diacetate. Cancer Chemother Rep 1961, 11, 81-6.

[11] Dabich, L.; Liepman, M. K., Cisplatin, VP-16-213 and MGBG (methylglyoxal bis guanylhydrazone) combination chemotherapy in refractory lymphoma, a phase II study. Invest New Drugs 1988, 6(3), 231-7.

[12] Coughlin, S. S.; Ekwueme, D. U., Breast cancer as a global health concern. Cancer Epidemiology 2009, 33(5), 315-318.

[13] Martin, A. R.; Carides, A. D.; Pearson, J. D.; Horgan, K.; Elmer M.; Schmidt, C.; Cai, B.; Chawla, S. P.; Grunberg, S. M., Functional relevance of antiemetic control: experience using the FLIE questionnaire in a randomised study of the NK-1 antagonist aprepitant. European Journal of Cancer 2003, 39(10), 1395-1401.

[14] Schnell, F. M., Chemotherapy-induced nausea and vomiting: the importance of acute antiemetic control. Oncologist 2003, 8(2), 18798.

[15] Yde, C. W.; Issinger, O. G., Enhancing cisplatin sensitivity in MCF-7 human breast cancer cells by down-regulation of Bcl-2 and cyclin D1. Int J Oncol 2006, 29(6), 1397-404.

[16] Skehan, P.; Storeng, R.; Scudiero, D.; Monks, A.; McMahon, J.; Vistica, D.; Warren, J. T.; Bokesch, H.; Kenney, S.; Boyd, M. R., New colorimetric cytotoxicity assay for anticancer-drug screening. J Natl Cancer Inst 1990, 82(13), 1107-12.

[17] Papazisis, K. T.; Geromichalos, G. D.; Dimitriadis, K. A.; Kortsaris, A. H., Optimization of the sulforhodamine B colorimetric assay. J Immunol Methods 1997, 208(2), 151-8.

[18] Hamid, R.; Rotshteyn, Y.; Rabadi, L.; Parikh, R.; Bullock, P., Comparison of alamar blue and MTT assays for high through-put screening. Toxicol In Vitro 2004, 18(5), 703-10.

[19] Scudiero, D. A.; Shoemaker, R. H.; Paull, K. D.; Monks, A.; Tierney, S.; Nofziger, T. H.; Currens, M. J.; Seniff, D.; Boyd, M. R., Evaluation of a soluble tetrazolium/formazan assay for cell growth and drug sensitivity in culture using human and other tumor cell lines. Cancer Res 1988, 48(17), 4827-33.

[20] Marques, M. P.; Gil, F. P.; Calheiros, R.; Battaglia, V.; Brunati, A. M.; Agostinelli, E.; Toninello, A., Biological activity of antitumoural MGBG: the structural variable. Amino Acids 2008, 34(4), 555-64.

[21] Ekelund, S.; Sjoholm, A.; Nygren, P.; Binderup, L.; Larsson, R., Cellular pharmacodynamics of the cytotoxic guanidino-containing drug CHS 828. Comparison with methylglyoxalbis(guanylhydrazone). Eur J Pharmacol 2001, 418(1-2), 39-45.

[22] Agostinelli, E.; Arancia, G.; Vedova, L. D.; Belli, F.; Marra, M.; Salvi, M.; Toninello, A., The biological functions of polyamine oxidation products by amine oxidases: perspectives of clinical applications. Amino Acids 2004, 27(3-4), 347-58.

[23] Agostinelli, E.; Marques, M. P.; Calheiros, R.; Gil, F. P.; Tempera, G.; Viceconte, N.; Battaglia, V.; Grancara, S.; Toninello, A., Polyamines: fundamental characters in chemistry and biology. Amino Acids 2010, 38(2), 393-403. 
[24] Kim, J. S.; Lee, J.; Chung, H. W.; Choi, H.; Paik, S. G.; Kim, I. G., Methylglyoxal-bis(guanylhydrazone), a polyamine analogue, sensitized [gamma]-radiation-induced cell death in HL-60 leukemia cells: Sensitizing effect of MGBG on [gamma]-radiation-induced cell death. Environmental Toxicology and Pharmacology 2006, 22(2), 160-166.

[25] Cepeda, V.; Fuertes, M. A.; Castilla, J.; Alonso, C.; Quevedo, C.; Perez, J. M., Biochemical mechanisms of cisplatin cytotoxicity. Anticancer Agents Med Chem 2007, 7(1), 3-18.

[26] Kartalou, M.; Essigmann, J. M., Mechanisms of resistance to cisplatin. Mutat Res 2001, 478(1-2), 23-43.

[27] Aung, H.; Mehendale, S.; Wang, C.; Xie, J.-T.; McEntee, E.; Yuan, C.-S., Cisplatin's tumoricidal effect on human breast carcinoma MCF-7 cells was not attenuated by American ginseng. Cancer Chemotherapy and Pharmacology 2007, 59(3), 369-374.
[28] Gonçalves, R. Evaluation of Antitumor Activity of MGBG in Breast Cancer Cells. University of Coimbra, Coimbra, 2010.

[29] Hah, S. S.; Stivers, K. M.; de Vere White, R. W.; Henderson, P. T., Kinetics of carboplatin-DNA binding in genomic DNA and bladder cancer cells as determined by accelerator mass spectrometry. Chem Res Toxicol 2006, 19(5), 622-6.

[30] Kozelka, J., Molecular origin of the sequence-dependent kinetics of reactions between cisplatin derivatives and DNA. Inorganica Chimica Acta 2009, 362(3), 651-668.

[31] Seppanen, P.; Alhonen-Hongisto, L.; Poso, H.; Janne, J., Sensitive enzymic determination of methylglyoxal bis(guanylhydrazone) in cultured cells and in animal tissues. FEBS Lett 1980, 111(1), 99103. 